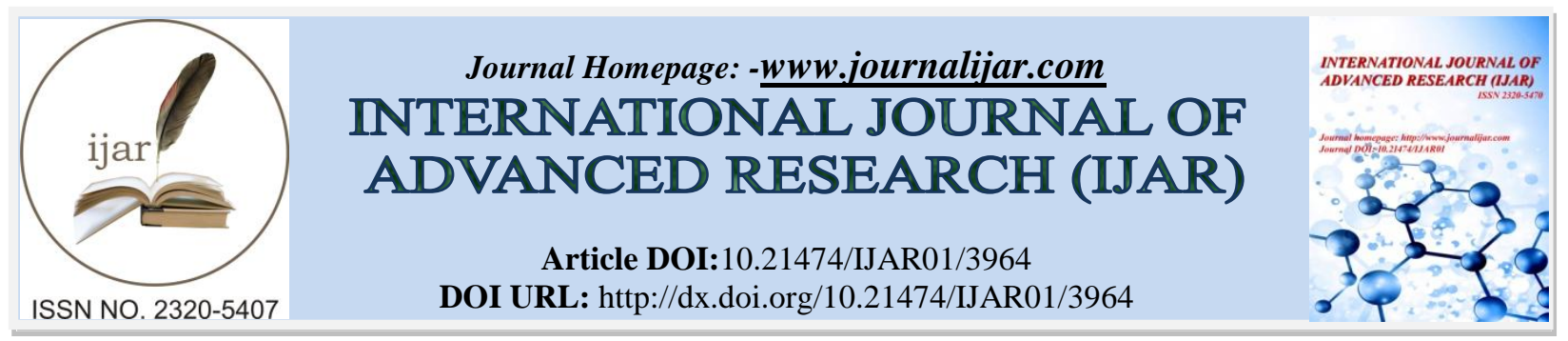

RESEARCH ARTICLE

\title{
COMPARISON OF PLATELET COUNT BY PERIPHERAL SMEAR METHOD AND BY ELECTRONIC COUNTER METHOD.
}

Monisha.K ${ }^{1}$ and Dr.Brundha M.P ${ }^{2}$.

1. II year BDS, Department of Pathology, Saveetha Dental College,Chennai.

2. Assistant professor, Department of Pathology, Saveetha Medical College,Chennai.

\section{Manuscript Info}

Manuscript History

Received: 13 February 2017

Final Accepted: 03 March 2017

Published: April 2017

Key words:-

Platelets,Peripheral smear,automated method.

\section{Abstract}

Aims \& Objective: This study was conducted to compare the platelet estimation by peripheral smear method and by automated method.

Materials and Methods: Platelet estimation was done in 50 patients who visited Saveetha Dental College, both male and female aged 60 and below by stained peripheral smear and automated method. Platelet counts were expressed in Mean \pm SD.

Statistical analysis was done by independent t test.

Results: CALCULATION-1(multiplier of 15,000)shows more significant value than other calculations.

Copy Right, IJAR, 2017,. All rights reserved.

\section{Introduction:-}

Platelets or thrombocytes are blood components which stops bleeding by clumping and clotting blood vessel injuries.[1]The appearance of platelets on a stained blood smear, appear as dark purple spots. The peripheral smear is used to examine platelets for size, shape, qualitative number, and clumping.Hemostasis is themain function of platelets.Platelets are nucleated cells with cytoplasm filled with granules. In a Leishman's stained peripheral blood preparation, they appear as small purple coloured bodies with irregular borders. Normal platelet count is 1,50,000 to 4,50,000 per cubic millimetre of blood. Platelet count may be increased (thrombocytosis) or decreased (thrombocytopenia) in clinical conditions [2]. There is mild prolongation of bleeding time when platelet count becomes 50,000 to 1,00,000 in case of a severe trauma, or surgery.[3]

For every sample of platelet count,platelet estimation is an important step especially when the count is lower or higher than the normal value [4].To estimate platelet count,the gold standard is the manual counting using phase contrastmicroscopy.[5]It plays a major role in the diagnosis of anemia and thrombocytopenia and in the identification of leukemia and lymphoma [7]. But this equipment may not be available in all the centres since the procedure is tedious and manual counts may not be reproducible. Automated blood cell counters have largely replaced the manual method of platelet counting for their accuracy and reduced analysis time. Limitations of using automated blood cell counters are its cost, stringent quality assurance and their unavailability in small peripheral centres.An abnormal platelet value obtained from automated values should be confirmed by peripheral smear method using Leishman's stained[5,6] . 
The primary objective of doing this research was to correlate the platelet count in stained and unstained peripheral smears keeping stained smears as the gold standard.

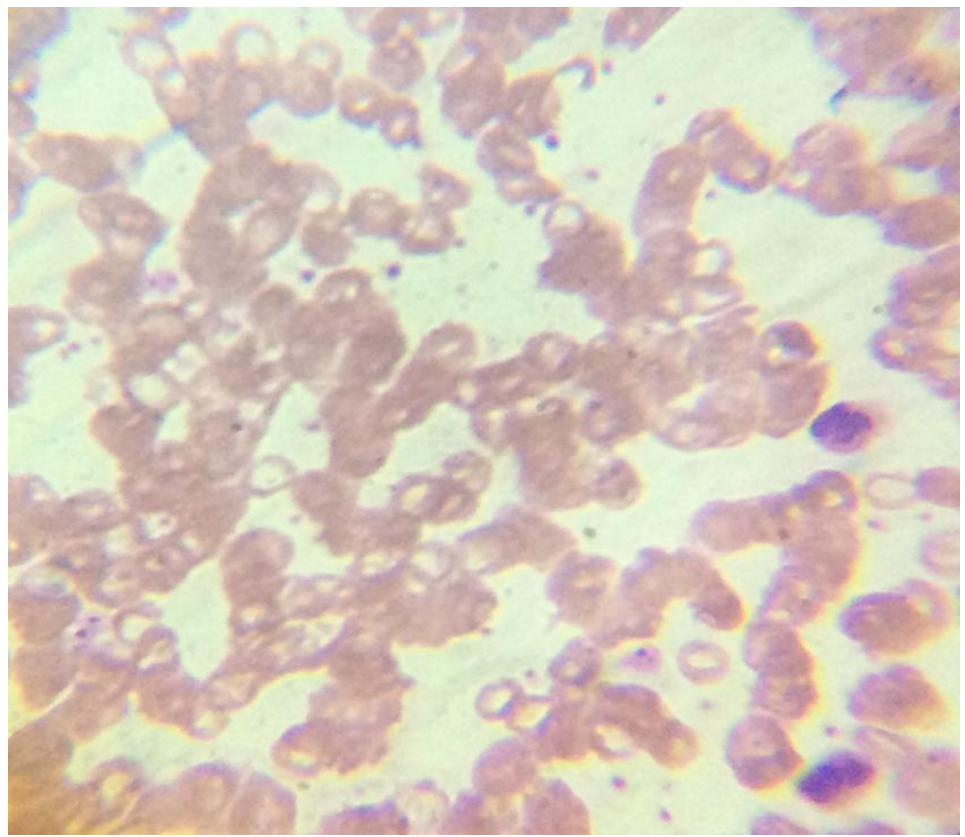

Fig:- Showing section of a slide from the stained leishman stain from a peripheral blood smear where the platelets appear as purple dots surrounded by red blood cells.

\section{Material and Methods:-}

Blood Samples:-

Blood samples were obtained from 50 patients ,aged 60 years and below visited our college for treatment.

All venous blood specimens were collected into tubes containing ethylenediaminetetraacetic acid ( or K3EDTA) 2 $\mathrm{ml}$ and then were analysed.

\section{Automated Method:-}

After thorough mixing of each blood sample on an auto- mated mixer for 3-5 min, a complete automated blood count was performed using an haematology analyser which was maintained and calibrated as recommended by the manufacturer.

\section{Manual Method:-}

Thin air-dried blood smears made after thorough mixing of each sample were stained manually with leishman's stain and examined under light microscopy with a X100 oil-immersion lens.

\section{Results:-}

Following are the results obtained from the study .The study involved counting of platelets with two calculations and the average of the two. 
1.Comparison Of Automated Platelet Count With Calculation -1.
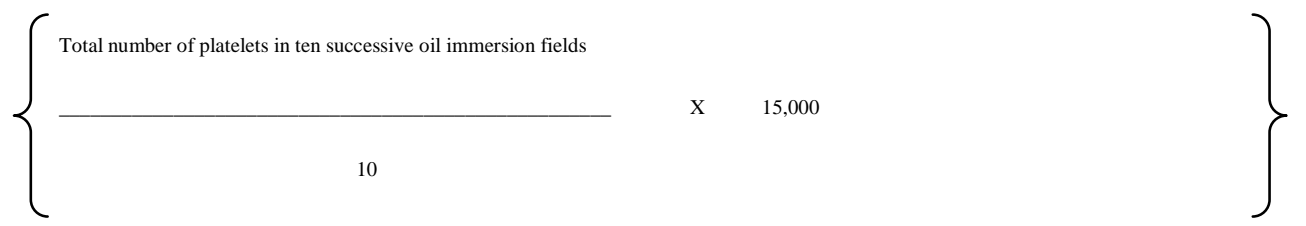

\begin{tabular}{|ll|r|c|c|c|}
\hline & GROUP & N & Mean & Std. Deviation & $\begin{array}{c}\text { Std. Error } \\
\text { Mean }\end{array}$ \\
\hline PLATELET COUNT & AUTOMATED & 50 & 347400.00 & 106714.381 & 15091.693 \\
& PLATELET COUNT & & & & \\
Calculation-1 & 50 & 363130.00 & 154391.161 & 21834.207 \\
\hline
\end{tabular}

2.Comparison Of Automated Platelet Count With Calculation-2.

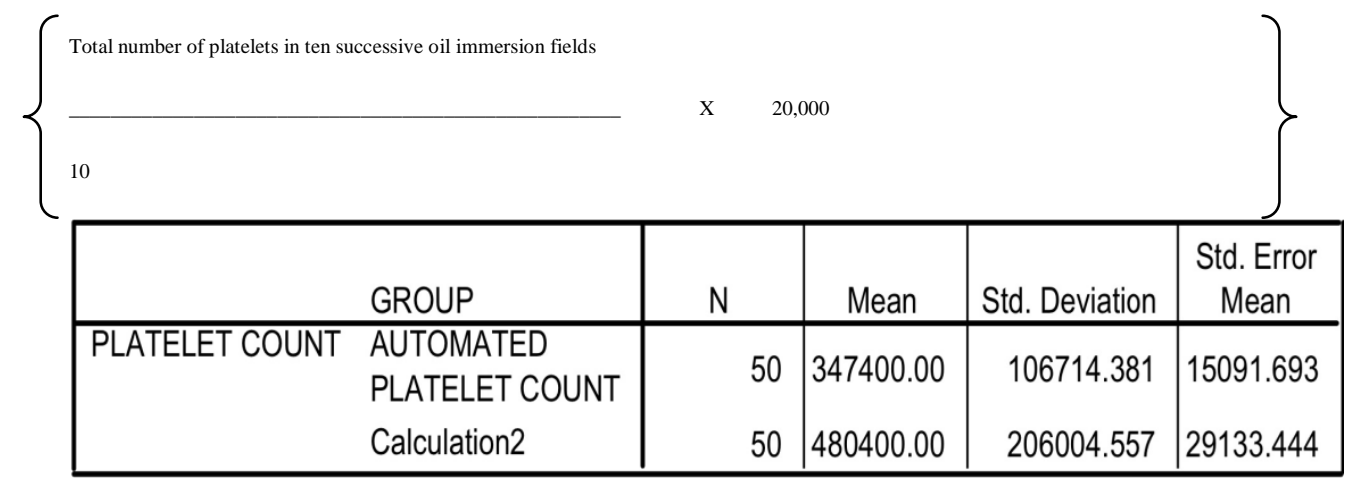

3.Comparison of Automated Platelets Count with the Average of the two calculations.

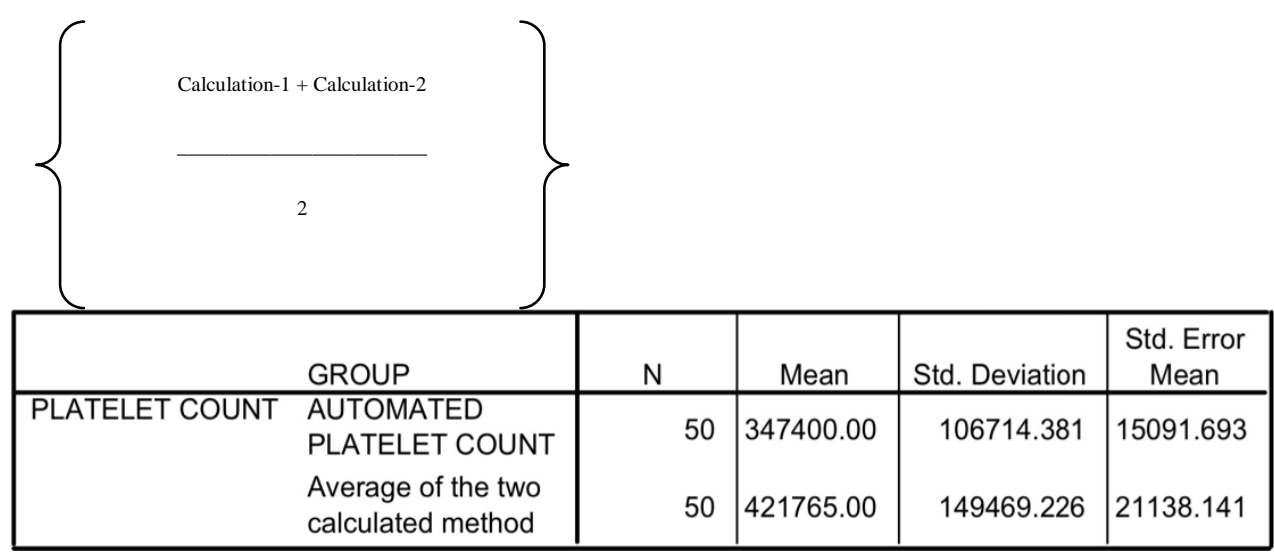


Fig1:-Calculation is more significant and closer to the automated platelet count.

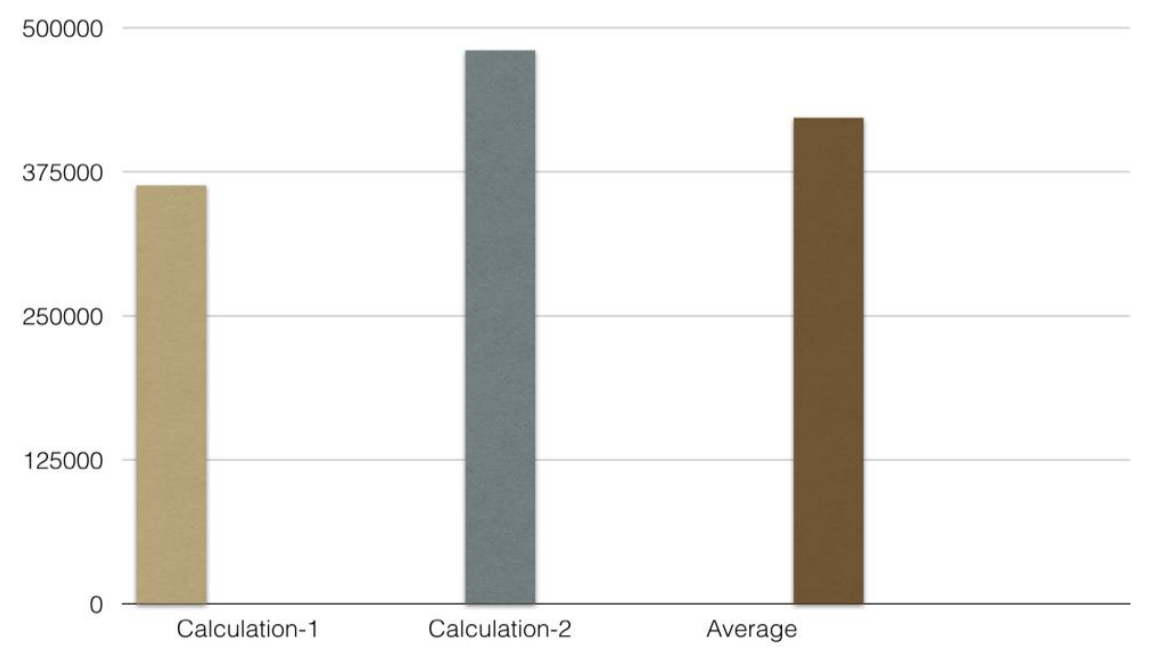

\section{Conclusion:-}

Our study concludes that that Calculation -1 is more significant compared to CALCULATION -2 and the average of the two.Fig-(1)

The statistical value of automated PLATELET COUNT is $347400 \pm 106714.381$, whereas the CALCULATION 1 (multiplier of 15,000 ) is $363130 \pm 154391$,CALCULATION-2(multiplier of 20,000) is $480400 \pm 206004.5$ and the average of the two is $421765 \pm 149469$.

Calculation 1 can be recommended in hospitals or places where PLATELET COUNT is being done manually through peripheral smear.

This study also concludes that though CALCULATION -1 is being more closest to the automatic value yet does not provide a more accurate value.Hence there is not much significance between manual and electronic counter method..

\section{References:-}

1. Laki K (Dec 8, 1972). "Our ancient heritage in blood clotting and some of its consequences". Annals of the New York Academy of Sciences. 202: 297-307.

2. Malaysian J Pathol 2014; 36(3) : $195-199$

3. V.K.Vignesh et al /J. Pharm. Sci. \& Res. Vol. 8(7), 2016, 642-644

4. Campbell, Neil A (2008) "Platelets are pinched-off cytoplasmic fragments of specialized bone marrow cells. They are about $2-3 \mu \mathrm{m}$ in diameter and have no nuclei. Platelets serve both structural and molecular functions in blood clotting." Biology (8thedn.) London.

5. Hutchison RE, McPherson RA, Schexneider KI. Basic examination of blood and bone marrow. In: McPherson RA, Pincus MR, editors. Henry's clinical diagnosis and management by laboratory methods. 22nd ed. Philadelphia: Elsevier Saunders; 2011. p. 509-35.

6. Moreno A, Menke D. Assessment of platelet num- bers and morphology in the 2 blood smear. Clin Lab Med. 2002; 22(1): 193-213.

7. Shagana. J.A /J. Pharm. Sci. \& Res. Vol. 6(4), 2014, 213-216. 